\title{
Perbandingan Metode Pembelajaran Mesin Berbasis Parametrik dan Non-Parametrik Untuk Klasifikasi Diabetic Retinopathy Imagery
}

\author{
Umniy Salamah \\ Fakultas Ilmu Komputer, Universitas Mercu Buana, Indonesia \\ umniy.salamah@mercubuana.ac.id
}

\begin{tabular}{l}
\hline \hline Article Info \\
\hline Article history: \\
Received, 04-06-2021 \\
Revised, 14-06-2021 \\
Accepted, 18-06-2021 \\
\hline Kata Kunci: \\
diabetic retinopathy \\
support vector machine \\
logistic regression \\
\hline \hline
\end{tabular}

\begin{abstract}
ABSTRAK
Untuk mendeteksi kerusakan retina dapat dilakukan bantuan algoritma pembelajaran mesin. Klasifikasi citra dengan menggunakan machine learning techniques (MLTs) dapat membantu proses penentuan pasien penderita diabetic retinopathy (DR). Teknik machine learning yang digunakan dapat dikelompokkan menjadi nonparametric (support vector machine) dan parametric (logistic regression). Tahap penelitian termasuk persiapan, ekstraksi fitur, normalisasi, klasifikasi, evaluasi dilakukan terhadap dataset gambar digital fundus yang disediakan oleh EyePACS. Model klasifikasi menggunakan model nonparametric (support vector machine) dan parametric (logistic regression). Sebagai hasil, metode logistic regression mendapatkan hasil akurasi (accuracy) sebesar 74\%, recall sebesar 74\%, presisi (precision) sebesar $60 \%$ dan F1-score sebesar $63 \%$. Selain itu, metode support vector machine mendapatkan hasil akurasi (accuracy) sebesar 74\%, recall sebesar 74\%, presisi (precision) sebesar 55\% dan F1-score sebesar 63\%.
\end{abstract}

\section{ABSTRACT}

Keywords:

diabetic retinopathy support vector machine logistic regression

\begin{abstract}
Machine learning algorithms can help detect retinal damage. Image classification using machine learning techniques (MLTs) can help the process of determining patients with diabetic retinopathy (DR). The machine learning techniques used can be grouped into nonparametric (support vector machine) and parametric (logistic regression). The research stages including preparation, feature extraction, normalization, classification, evaluation were carried out on the fundus digital image dataset provided by EyePACS. The classification model uses nonparametric (support vector machine) and parametric (logistic regression) models. As a result, the logistic regression method obtained an accuracy of $74 \%$, recall of $74 \%$, precision of $60 \%$ and F1score of $63 \%$. In addition, the support vector machine method gets $74 \%$ accuracy, $74 \%$ recall, $55 \%$ precision and $63 \% \mathrm{~F} 1$-score.
\end{abstract}

This is an open access article under the CC BY-SAlicense.

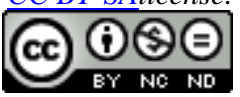

\author{
Penulis Korespondensi: \\ Umniy Salamah \\ Fakultas Ilmu Komputer \\ Universitas Mercu Buana, Indonesia \\ Email: umniy.salamah@mercubuana.ac.id
}

\section{PENDAHULUAN}

Penyakit kerusakan retina pada mata atau yang disebut diabetic retinopathy (DR) adalah trigger paling sering muncul yang menyebabkan kebutaan dalam populasi kerja. Dengan adanya deteksi lebih awal dan pengobatan tepat waktu dapat menjadi upaya untuk mencegah hilangnya penglihatan dan kebutaan pada pasien dengan komplikasi diabetes [1], [2].

Berdasarkan hasil prediksi mengenai proyeksi jumlah orang dengan diabetes akan meningkat di setiap kategori usia. Hal ini akan menyebabkan berkurangnya rasio seimbang antara penyedia layanan kesehatan perawatan mata yang berkualitas dengan jumlah pasien. Kondisi ini akan menjadi tantangan dalam bidang kesehatan dalam menyediakan layanan kesehatan masyarakat terbaik untuk merawat pasien kerusakan retina 
JSAI: Journal Scientific and Applied Informatics

Vol. 4, No. 2, Bulan Tahun, hal. 193 198

E-ISSN: 2614-3054; P-ISSN: 2614-3062, accredited by Kemenristekdikti, Sinta 5

DOI: 10.36085

akibat komplikasi diabetes. Alternatif untuk untuk permasalah ini adalah dengan memberikan layanan deteksi dini pada pasien diabetes pada layanan kesehatan mata [3]-[11].

Untuk mendeteksi kerusakan retina dapat dilakukan bantuan algoritma pembelajaran mesin. Klasifikasi citra dengan menggunakan machine learning techniques (MLTs) dapat membantu proses penentuan pasien penderita diabetic retinopathy (DR). Teknik machine learning yang digunakan dapat dikelompokkan menjadi nonparametric (sebagai contoh, support vector machine) dan parametric (logistic regression). Setiap kelompok algoritma atau teknik ini memiliki karakteristik masing-masing terutama dalah hal properties relationship dan penggunaan pengetahuan knowledge [12]-[16].

Penelitian terkait komparasi model nonparametric dan parametric telah dilakukan oleh beberapa peneliti antara lain Park et al (2016), Kotlar et al (2019), Fernandez-Zelaia et al (2019), Mondal et al (2020) dan Liu et al. (2020). Park et al (2016) melakukan penelitian menggunakan teknik parametric dan non-parametric untuk menganalisis biaya market impact, Fernandez-Zelaia et al (2019) meneliti mengenai konduktivitas hidrolik tanah, Mondal et al (2020) membahas mengenai prediksi crash severity dan Liu et al. (2020) menlakukan pemetaan perbaikan hutan. Namun, untuk bidang atau dataset citra diabetic retinopathy (DR) belum banyak dilakukan riset untuk mengenai perbandingan performa model nonparametric dan parametric [17]-[21].

Berdasarkan latar belakang tersebut, penelitian mencoba melakukan penelitian untuk membandingkan hasil kinerja metode pembelajaran mesin berbasis parametrik dan non-parametrik untuk klasifikasi diabetic retinopathy imagery. Penelitian ini adalah penelitian pendahuluan untuk pengembangan aplikasi medis untuk deteksi kerusakan retina mata.

\section{METODE PENELITIAN}

Eksperimen riset akan dilakukan melalui lima tahapan penelitian, antara lain data preparation, feature extraction dan selection, data training, parameter tuning dan evaluasi, seperti yang terlihat pada Gambar 1.

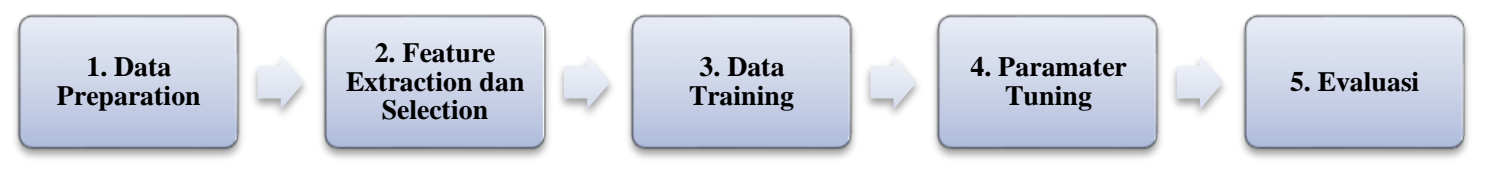

Gambar 1 Tahapan Penelitian

Tahap pertama adalah data preparation yang dilakukan dengan cara melakukan resized ukuran dataset untuk mempercepat komputasi. Kemudian memisahkan data training dan data testing dengan presentase $70 \%$ data training, dan 30\% data testing serta mengubah data dan label kedalam format HDF5.

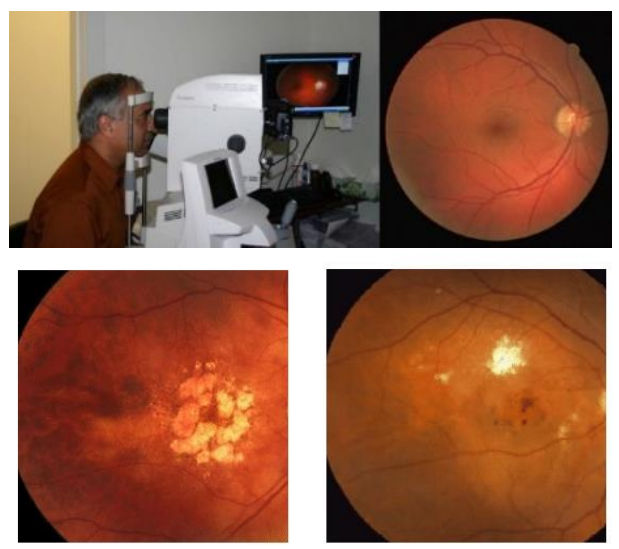

Gambar 2 Contoh Dataset Citra

Sumber: [22]

Tahap kedua adalah feature extraction dan selection. Untuk feature extraction yang dilakukan dengan menggunakan 3 global feature descriptors antara lain color histogram, Hu Moments dan Haralick Texture. Ketiga fitur di concate (digabung) untuk mendapatkan 1 fitur dan disimpan kedalam format HDF5. Setelah ekstraksi fitur dan concatenating, proses selanjutnya adalah normalisasi fitur yang telah dibuat yaitu antara range [0-1] menggunakan function MinMaxScaler () yang ada di scikit-learns. Proses akhir dari tahap ini adalah, penyimpanan hasil akhir ke dalam format hdf5 (.h5).

Tahap ketiga adalah data training. Setelah proses extracting, concenating, dan normalisasi fitur selanjutnya dilakukan training classifiers. Pada tahap ini dikembangkan machine learning models 
menggunakan scikit-learn. Model yang digunakan dalam penelitian ini adalah model nonparametric (support vector machine) dan parametric (logistic regression). dan menggunakan $K$-fold cross validation dengan $\mathrm{k}=10$. Setelah mendapatkan model terbaik, selanjutnya menguji model menggunakan data testing. Untuk meningkatkan performansi model dilakukan tuning parameter pada masing-masing model nonparametric (support vector machine) dan parametric (logistic regression). Setelah itu dilakukan evaluasi yang dilakukan adalah menghitung akurasi, precision, F1 score, dan kappa-value.

\section{HASIL DAN ANALISIS}

Tahap penelitian termasuk persiapan, ekstraksi fitur, normalisasi, klasifikasi, evaluasi dilakukan terhadap dataset gambar digital fundus yang disediakan oleh EyePACS. Sebelum melakukan pengolahan data, penelitian ini memisahkan data training dan data testing dengan presentase $70 \%$ untuk data training, dan $30 \%$ untuk data testing serta mengubah data dan label kedalam format HDF5.

Dataset terdiri dari 2500 fundus images yang disediakan oleh EyePACS untuk umum. Pengolahan data menggunakan scikit-learn sebagai machine learning library dan Python sebagai bahasa pemrograman, sedangkan evaluasi menggunakan perhitungan akurasi, presisi, recall dan F1 score sebagai hasil penelitian.

Pada penelitian ini digunakan model nonparametric (support vector machine) dan parametric (logistic regression). Metode logistic regression (LR) merupakan metode yang robust di antara metode statistik pembelajaran mesin yang dikembangkan dari teknik linear regresi untuk masalah dimana output berupa variable kategorikal. Dalam memproses data, metode LR mendefinisikan variabel respon dengan satu atau beberapa variabel prediktor-nya [23]-[26].

Seperti halnya algoritma berbasis regresi linear lainnya, metode logistic regression (LR) mendefinisikan variable predictor dan variable response. Pada logistic regression (LR) variable response memiliki nilai dikotomus (nilai berupa 0 dan 1), sehingga algoritma tersebut mengikuti distribusi Bernoulli yang menggunakan fungsi probabilistik [27]-[30]:

$$
f\left(y_{i}\right)=\pi\left(x_{i}\right)^{\left(y_{i}\right)}\left(1-\pi\left(x_{i}\right)\right)^{\left(1-y_{i}\right)}
$$

dengan $y_{i}=0,1$, dan untuk

$$
\pi(x)=\frac{\exp \left(\beta_{0}+\beta_{1} x_{1}+\cdots+\beta_{p} x_{p}\right)}{1+\exp \left(\beta_{0}+\beta_{1} x_{1}+\cdots+\beta_{p} x_{p}\right)}
$$

Persamaan diatas kemudian ditransformasikan menggunakan transformasi logit $\pi(x)$ untuk memperoleh fungsi $g(x)$ yang linear untuk nilai parameternya. Untuk mempermudah untuk mencari parameter regresinya dapat menggunakan persamaan berikut [27]-[30]:

$$
g(x)=\ln \left[\frac{\pi(x)}{1-\pi(x)}\right]=\beta_{0}+\beta_{1} x_{1}+\cdots+\beta_{p} x_{p}
$$

Metode selanjutnya adalah support vector machine (SVM). Metode ini merupakan algoritma machine learning yang dapat menentukan bidang pemisah data (hyperplane) secara optimal dalam sebuah input space. Jika pengukuran margin antara batasan kelas pada ruang input dapat maksimal, maka hasil terbaik dari hyperplane akan didapatkan. Selain itu, model atau algoritma support vector machine (SVM) merupakan salah satu bentuk linear classifier. Namun, support vector machine (SVM) ini juga dapat digunakan untuk problem linear dengan cara memetakan input space ke ruang high-dimensional yang ada pada konsep kernel trick dengan [31]-[34].

Untuk melakukan evaluasi model algoritma, penelitian ini menggunakan nilai akurasi, presisi, recall dan F1score dengan penjelasan sebagai berikut [35], [36]:

1. Akurasi (accuracy) adalah pengukuran kinerja yang merupakan rasio pengolahan data yang diprediksi dengan benar terhadap total data yang diolah. Jika pada penelitian ini didapatkan akurasi sebesar 0,7392 , maka model algoritma tersebut mencapai akurasi sebesar $74 \%$.

2. Presisi (precision) adalah pengukuran kinerja yang merupakan rasio surveilans data positif yang diprediksi dengan benar terhadap total surveilans data positif yang diprediksi. Jika pada penelitian ini didapatkan presisi sebesar 0,6043 , maka model algoritma ini memiliki presisi mencapai $60 \%$.

3. Recall adalah pengukuran kinerja yang merupakan rasio surveilans data positif yang diprediksi dengan benar terhadap semua surveilans data di kelas aktual "yes". Pada penelitian ini didapatkan 
JSAI: Journal Scientific and Applied Informatics

Vol. 4, No. 2, Bulan Tahun, hal. 193 198

E-ISSN: 2614-3054; P-ISSN: 2614-3062, accredited by Kemenristekdikti, Sinta 5

DOI: 10.36085

nilai recall deteksi kerusakan retina sebesar 0,7392 yang berarti model algoritma ini memiliki nilai recall sebesar $74 \%$.

4. F1 score adalah pengukuran kinerja yang merupakan rata-rata tertimbang dari nilai presisi dan recall. Jika penelitian mendapatkan F1-score sebesar 0,6317, maka model algoritma ini memiliki F1 Score mencapai $63 \%$.

Dari hasil pengolahan data, hasil evaluasi beberapa classifier menggunakan metode logistic regression (LR) dan metode support vector machine (SVM) dapat dilihat pada Tabel dibawah ini.

Tabel 1 Hasil Evaluasi Model Algoritma

\begin{tabular}{|l|l|l|l|l|l|}
\hline \multicolumn{1}{|c|}{ Metode } & \multicolumn{1}{c|}{ Accuracy } & \multicolumn{1}{c|}{ F1-score } & \multicolumn{1}{c|}{ Recall } & \multicolumn{1}{c|}{ Precision } & \multicolumn{1}{c|}{ Kappa } \\
\hline Logistic Regression & 0.7392 & 0.6317 & 0.7392 & 0.6043 & 0.0051 \\
\hline SVM & 0.7401 & 0.6295 & 0.7401 & 0.5477 & 0.0 \\
\hline
\end{tabular}

Untuk menyajikan performance metric pada penelitian ini, termasuk data total, kelas total, label prediksi (kelas), label benar (kelas), penelitian ini menggunakan confusion matrix seperti yang dapat dilihat sebagai berikut. Ada lima kelas dalam penelitian ini dengan uraian sebagai berikut:

- 0 - No retina damage with diabetic retinopathy

- 1 - Mild

- 2 - Moderate

- 3 - Severe

- 4 - Proliferative diabetic retinopathy

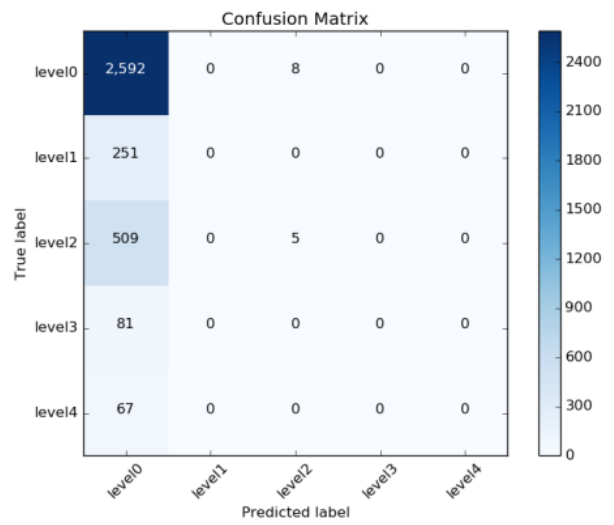

(a) Model logistic regression (LR)

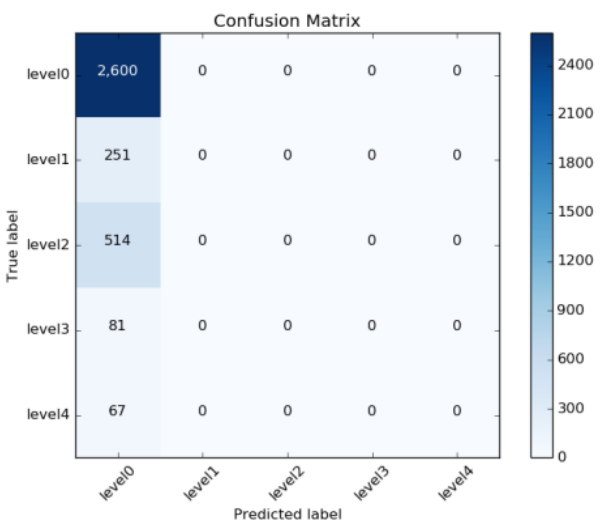

(b) Model support vector machine (SVM)

Gambar 3 Confusion Matrix

\section{KESIMPULAN}

Untuk mendeteksi kerusakan retina dapat dilakukan bantuan algoritma pembelajaran mesin. Klasifikasi citra dengan menggunakan machine learning techniques (MLTs) dapat membantu proses penentuan pasien penderita diabetic retinopathy (DR). Teknik machine learning yang digunakan dapat dikelompokkan menjadi nonparametric (support vector machine) dan parametric (logistic regression). Penelitian terkait komparasi model nonparametric dan parametric telah dilakukan oleh beberapa peneliti antara lain Park et al (2016), Kotlar et al (2019), Fernandez-Zelaia et al (2019), Mondal et al (2020) dan Liu et al. (2020. Namun, untuk bidang atau dataset citra diabetic retinopathy (DR) belum banyak dilakukan riset untuk mengenai perbandingan performa model nonparametric dan parametric. Sebagai hasil, metode logistic regression mendapatkan hasil akurasi (accuracy) sebesar 74\%, recall sebesar 74\%, presisi (precision) sebesar 60\% dan F1-score sebesar 63\%. Selain itu, metode support vector machine mendapatkan hasil akurasi (accuracy) sebesar 74\%, recall sebesar 74\%, presisi (precision) sebesar 55\% dan F1-score sebesar 63\%. 


\section{UCAPAN TERIMA KASIH}

Terima kasih kepada Pusat Penelitian (Biro Penelitian, Pengabdian Masyarakat \& Publikasi UMB) yang telah mendanai penelitian ini dengan kontrak penelitian 02-5/928/B-SPK/V/2020.

\section{REFERENSI}

[1] A. K. Poddar et al., "Prevalence and causes of avoidable blindness and visual impairment, including the prevalence of diabetic retinopathy in Siwan district of Bihar, India: A population-based survey," Indian J. Ophthalmol., vol. 68, no. 2, p. 375, 2020.

[2] F. C. Sasso et al., "Telemedicine for screening diabetic retinopathy: The NO BLIND Italian multicenter study," Diabetes. Metab. Res. Rev., vol. 35, no. 3, p. e3113, 2019.

[3] N. Gerrits et al., "Age and sex affect deep learning prediction of cardiometabolic risk factors from retinal images," Sci. Rep., vol. 10, no. 1, pp. 1-9, 2020.

[4] K. Al-Fawaz, K. Al Rubaie, Y. Zia, and R. Khandekar, "Comparison of Digital Retinal Images and Information Tele-Transferred Through the Hala System to Manual Image Transfer of Diabetic Patients from Primary Health Care Centers in Riyadh," Telemed. e-Health, 2020.

[5] A. Waqas, S. H. Teoh, L. V. Lapão, L. A. Messina, and J. C. Correia, "Harnessing Telemedicine for the Provision of Health Care: Bibliometric and Scientometric Analysis," J. Med. Internet Res., vol. 22, no. 10, p. e18835, 2020.

[6] D. Ramayanti et al., "Tuberculosis Ontology Generation and Enrichment Based Text Mining," in 2020 International Conference on Information Technology Systems and Innovation (ICITSI), 2020, pp. 429434.

[7] V. Ayumi and H. Noprisson, "Rancang Bangun Aplikasi Monitoring Pemberian Obat Bagi Pasien," $J$. Sci. Appl. Informatics, vol. 1, no. 1, pp. 8-12, 2018.

[8] V. Ayumi, "Application of Machine Learning for SARS-CoV-2 Outbreak," Int. J. Sci. Res. Sci. Eng. Technol., vol. 7, no. 5, 2020.

[9] P. Sukmasetya, F. Nurhidayati, I. Permatasari, A. Rahmah, D. I. Sensuse, and H. Noprisson, "Developing mobile expert web-based system using brainstorming method: Case: Tetanus and botulism diagnosis and treatment in goat," 2017 Int. Conf. Inf. Technol. Syst. Innov. ICITSI 2017 - Proc., vol. 2018-Janua, pp. 303-308, 2017.

[10] H. Noprisson, "Challenges and Benefits of Knowledge Management Practices in Electronic Government," Int. J. Sci. Res. Comput. Sci. Eng. Inf. Technol., vol. 5, no. 4, 2019.

[11] V. Ayumi, "Studi Pendahuluan: Pengembangan Aplikasi m-BCARE Untuk Pasien Penderita Kanker Payudara," JUSIBI (Jurnal Sist. Inf. dan E-Bisnis), vol. 3, no. 1, pp. 26-33, 2021.

[12] D. Ramayanti and U. Salamah, "Complaint Classification Using Support Vector Machine for Indonesian Text Dataset," Int. J. Sci. Res. Comput. Sci. Eng. Inf. Technol., vol. 3, no. 7, pp. 179-184, 2018.

[13] D. Ramayanti, "Comparison of Random Forest and Support Vector Machine for Indonesian Tweet Complaint Classification,” Int. J. Sci. Res. Comput. Sci. Eng. Inf. Technol., vol. 5, no. 6, pp. 202-207, 2019.

[14] U. Salamah, "A Comparison of Text Classification Techniques Applied to Indonesian Text Dataset," Int. J. Sci. Res. Comput. Sci. Eng. Inf. Technol., vol. 5, no. 6, pp. 217-222, 2019.

[15] D. Ramayanti and U. Salamah, "Text Classification on Dataset of Marine and Fisheries Sciences Domain using Random Forest Classifier," Int. J. Comput. Tech, vol. 5, no. 5, pp. 1-7, 2018.

[16] M. Sadikin, D. Ramayanti, and A. P. Indrayanto, "The Graded CNN Technique to Identify Type of Food as The Preliminary Stages to Handle the Issues of Image Content Abundant," in Proceedings of the 2020 12th International Conference on Computer and Automation Engineering, 2020, pp. 108-113.

[17] S. Park, J. Lee, and Y. Son, "Predicting market impact costs using nonparametric machine learning models," PLoS One, vol. 11, no. 2, p. e0150243, 2016.

[18] A. M. Kotlar, B. V Iversen, and Q. de Jong van Lier, "Evaluation of parametric and nonparametric machine-learning techniques for prediction of saturated and near-saturated hydraulic conductivity," Vadose Zo. J., vol. 18, no. 1, pp. 1-13, 2019.

[19] A. R. Mondal, M. A. E. Bhuiyan, and F. Yang, "Advancement of weather-related crash prediction model using nonparametric machine learning algorithms," SN Appl. Sci., vol. 2, no. 8, pp. 1-11, 2020.

[20] B. Liu, L. Gao, B. Li, R. Marcos-Martinez, and B. A. Bryan, "Nonparametric machine learning for mapping forest cover and exploring influential factors," Landsc. Ecol., vol. 35, no. 7, pp. 1683-1699, Jul. 2020 .

[21] P. Fernandez-Zelaia, Y. C. Yabansu, and S. R. Kalidindi, "A Comparative Study of the Efficacy of Local/Global and Parametric/Nonparametric Machine Learning Methods for Establishing Structure- 
Property Linkages in High-Contrast 3D Elastic Composites," Integr. Mater. Manuf. Innov., vol. 8, no. 2, pp. 67-81, 2019.

[22] S. Aslani and H. Sarnel, "A new supervised retinal vessel segmentation method based on robust hybrid features," Biomed. Signal Process. Control, vol. 30, pp. 1-12, 2016.

[23] J. Wu, H. Zhang, and X. Ran, "Nonparametric regression algorithm for short-term traffic flow forecasting based on data reduction and support vector machine," J. Highw. Transp. Res. Dev. (English $E d$., vol. 14, no. 3, pp. 96-103, 2020.

[24] Z. Wang, H. Xu, L. Xia, Z. Zou, and C. G. Soares, "Kernel-based support vector regression for nonparametric modeling of ship maneuvering motion," Ocean Eng., vol. 216, p. 107994, 2020.

[25] A. Soula, K. Tbarki, R. Ksantini, S. Ben Said, and Z. Lachiri, "A novel incremental Kernel Nonparametric SVM model (iKN-SVM) for data classification: An application to face detection," Eng. Appl. Artif. Intell., vol. 89, p. 103468, 2020.

[26] A. Ghasemzadeh, B. E. Hammit, M. M. Ahmed, and R. K. Young, "Parametric ordinal logistic regression and non-parametric decision tree approaches for assessing the impact of weather conditions on driver speed selection using naturalistic driving data," Transp. Res. Rec., vol. 2672, no. 12, pp. $137-$ $147,2018$.

[27] D. W. Hosmer Jr, S. Lemeshow, and R. X. Sturdivant, Applied logistic regression. Vol. 398. John Wiley \& Sons, 2013.

[28] C. I. Sánchez, R. Hornero, A. Mayo, and M. García, "Mixture model-based clustering and logistic regression for automatic detection of microaneurysms in retinal images," in Medical Imaging 2009: Computer-Aided Diagnosis, 2009, vol. 7260, p. 72601M.

[29] S. Nusinovici et al., "Logistic regression was as good as machine learning for predicting major chronic diseases," J. Clin. Epidemiol., vol. 122, pp. 56-69, 2020.

[30] M. De Cock, R. Dowsley, A. C. A. Nascimento, D. Railsback, J. Shen, and A. Todoki, "High performance logistic regression for privacy-preserving genome analysis," BMC Med. Genomics, vol. 14, no. 1, pp. 1-18, 2021.

[31] V. N. Vapnik, "An Overview of Statistical Learning Theory," vol. 10, no. 5, pp. 988-999, 1999.

[32] D. W. Hosmer and S. Lemeshow, “Applied Logistic Regression.” New York: John Wiley \& Sons, Inc, 2000.

[33] S. R. Manne et al., "Efficient Screening of Diseased Eyes based on Fundus Autofluorescence Images using Support Vector Machine," arXiv Prepr. arXiv2104.08519, 2021.

[34] P. R. R. Chandni, "Anomaly Prognostication of Retinal Fundus Images Using EALCLAHE Enhancement and Classifying with Support Vector Machine," in Machine Learning, Deep Learning and Computational Intelligence for Wireless Communication, Springer, 2021, pp. 605-617.

[35] K. P. Shung, "Accuracy; Precision; Recall or F1?," Towards Data Science, 2018. [Online]. Available: https://towardsdatascience.com/accuracy-precision-recall-or-f1-331fb37c5cb9. [Accessed: 12-Mar2020].

[36] R. Joshi, "Accuracy, Precision, Recall \& F1 Score: Interpretation of Performance Measures," Exsilio Solutions, 2016. [Online]. Available: https://blog.exsilio.com/all/accuracy-precision-recall-f1-scoreinterpretation-of-performance-measures/. [Accessed: 12-Mar-2020]. 